Subscriber access provided by Library, Special Collections and Museums, University of Aberdeen

\title{
Carbon Capture by Metal Oxides: Unleashing the Potential of the (111) Facet
}

Greg A. Mutch, Sarah Shulda, Alan J. McCue, Martin J. Menart, Cristian V. Ciobanu, Chilan Ngo, James A. Anderson, Ryan M. Richards, and David Vega-Maza

J. Am. Chem. Soc., Just Accepted Manuscript • DOI: 10.1021/jacs.8b01845 • Publication Date (Web): 19 Mar 2018

Downloaded from http://pubs.acs.org on March 20, 2018

\section{Just Accepted}

"Just Accepted" manuscripts have been peer-reviewed and accepted for publication. They are posted online prior to technical editing, formatting for publication and author proofing. The American Chemical Society provides "Just Accepted" as a service to the research community to expedite the dissemination of scientific material as soon as possible after acceptance. "Just Accepted" manuscripts appear in full in PDF format accompanied by an HTML abstract. "Just Accepted" manuscripts have been fully peer reviewed, but should not be considered the official version of record. They are citable by the Digital Object Identifier (DOI®). "Just Accepted" is an optional service offered to authors. Therefore, the "Just Accepted" Web site may not include all articles that will be published in the journal. After a manuscript is technically edited and formatted, it will be removed from the "Just Accepted" Web site and published as an ASAP article. Note that technical editing may introduce minor changes to the manuscript text and/or graphics which could affect content, and all legal disclaimers and ethical guidelines that apply to the journal pertain. ACS cannot be held responsible for errors or consequences arising from the use of information contained in these "Just Accepted" manuscripts. 


\title{
Carbon Capture by Metal Oxides: Unleashing the Potential of the (111) Facet
}

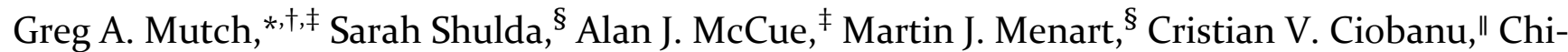 \\ lan Ngo, ${ }^{\S}$ James A. Anderson, ${ }^{\ddagger}$ Ryan M. Richards ${ }^{\S}$ and David Vega-Maza ${ }^{\ddagger}$ \\ ${ }^{\dagger}$ School of Engineering, Newcastle University, Newcastle upon Tyne, NE1 $7 R U$, United Kingdom. \\ ${ }^{\ddagger}$ School of Engineering, University of Aberdeen, Aberdeen, AB24 3FX, United Kingdom. \\ ${ }^{\S}$ Department of Chemistry and Geochemistry, Colorado School of Mines, Golden, Colorado, United States. \\ "Department of Mechanical Engineering and Materials Science Program, Colorado School of Mines, Golden, Colo- \\ rado, United States.
}

\begin{abstract}
Solid metal oxides for carbon capture exhibit reduced adsorption capacity following high temperature exposure, due to surface area reduction by sintering. Furthermore, only low coordinate corner/edge sites on the thermodynamically stable (100) facet display favourable binding towards $\mathrm{CO}_{2}$, providing inherently low capacity. The (111) facet however, exhibits a high concentration of low coordinate sites. In this work, $\mathrm{MgO}(111)$ nanosheets displayed high capacity for $\mathrm{CO}_{2}$, as well as $\mathrm{a} \approx 65 \%$ increase in capacity despite $\mathrm{a} \approx 30 \%$ reduction in surface area following sintering (o.77 $\mathrm{mmol} \mathrm{g}^{-}$ ${ }^{1} @ 227 \mathrm{~m}^{2} \mathrm{~g}^{-1}$ vs $1.28 \mathrm{mmol} \mathrm{g}^{-1} @ 154 \mathrm{~m}^{2} \mathrm{~g}^{-1}$ ). These results, unique to $\mathrm{MgO}(111)$ suggest intrinsic differences in the effects of sintering on basic site retention. Spectroscopic and computational investigations provided a new structure-activity insight; the importance of high temperature activation to unleash the capacity of the polar (111) facet of $\mathrm{MgO}$. In summary, we present the first example of a faceted sorbent for carbon capture and challenge the assumption that sintering is necessarily a negative process; here we leverage high temperature conditions for facet-dependent surface activation.
\end{abstract}

\section{Introduction}

Carbon capture, utilisation and storage (CCUS) is a portfolio of processes to combat anthropogenic climate change. ${ }^{1}$ Capture is most economically viable for slowing $\mathrm{CO}_{2}$ release at point sources, e.g. combustion power generation plants. Direct air capture is increasingly discussed, ${ }^{2-4}$ to immediately reduce atmospheric $\mathrm{CO}_{2}$ concentration. CCUS allows the continued use of fossil fuels, or results in net negative carbon emissions, when in combination with bioenergy. ${ }^{5,6}$ Utilisation refers to the subsequent use of $\mathrm{CO}_{2}$ in the synthesis of chemicals or enhanced oil recovery, in order to add value. ${ }^{7,8}$ Storage is generally the disposal of captured $\mathrm{CO}_{2}$ in geological formations. ${ }^{9}$

Regardless of the fate of $\mathrm{CO}_{2}$, it remains the case that capture is the most costly stage of CCUS, ${ }^{10}$ due to the immense volumes to be handled. Cyclic absorptiondesorption of $\mathrm{CO}_{2}$ using aqueous amines is inefficient and expensive, generating significant interest in developing new "task-specific" materials as replacements. ${ }^{113}$ Solid adsorption-desorption cycles, "looping" processes, offer many advantages over amine scrubbing. They can be distinguished chiefly by their role: the supply of $\mathrm{O}_{2}$ from air for combustion (providing inherent carbon capture) $)^{14}$ insitu $\mathrm{CO}_{2}$ sorption during $\mathrm{H}_{2}$ production, ${ }^{15}$ and the removal of $\mathrm{CO}_{2}$ from flue gases. ${ }^{16}$ Solid oxide adsorbents used in these processes, e.g. $\mathrm{CaO}$ or $\mathrm{MgO}$, experience particularly harsh environments. They are fluidised, handled at high temperature, and repeatedly cycled between oxidation/reduction or carbonation/calcination reactors. Sintering dramatically reduces sorbent performance, acutely evident in high temperature $\mathrm{CO}_{2}$ adsorbents ${ }^{17}$ leading to creative synthetic efforts in producing sintering-resistant materials. ${ }^{18-20}$

For any adsorbent, the initial gas-solid reaction/interaction must occur at the surface. Using the carbonation of $\mathrm{CaO}$ in calcium looping as a pertinent example, carbonates first form at the surface, subsequently migrating to the bulk. ${ }^{21}$ The capacity of sorbents proposed for low temperature carbon capture is entirely limited to surface interaction, resulting in a race to produce ever increasing surface areas - exemplified by metal-organic frameworks (MOFs). ${ }^{22,23}$ This approach is likely to fail for solid oxides such as $\mathrm{CaO}$ or $\mathrm{MgO}$ due to sintering over large numbers of high temperature cycles. Increased surface area has been shown to enhance capacity, only in a limited number of cycles. ${ }^{24-26}$ Considered far less often for $\mathrm{CO}_{2}$ adsorbents, if at all, is the synthetic control and subsequent utilisation of exposed "favourable" crystalline facets. This is surprising considering entire fields (e.g. catalysis) have developed largely by controlling this aspect of solids. ${ }^{27-30}$

In an attempt to bridge this concept with carbon capture, we considered that prominent high temperature 
adsorbents include isometric crystals of the rock-salt structure (space group Fm3m), more specifically group 2 alkaline earth metal oxides, e.g. $\mathrm{MgO}$. In this structure, $\mathrm{Mg}$ and $\mathrm{O}$ atoms occupy octahedral geometry, forming independent face-centred cubic lattices, which merge together to produce an alternating cation/anion pattern propagating in three dimensions. The thermodynamically favoured (100) facet can easily be envisioned as an atomic checkerboard pattern. The (111) facet can be visualised as alternating polar layers of cation and anion (Figure 1a), with surface termination dependant on the environment. In O-rich conditions the facet will be oxygen terminated. ${ }^{31}$ The polar (111) facet has been shown to be stable at the nano-scale ${ }^{32,33}$ or when hydroxylated..$^{34-36} \mathrm{Ab}$ initio calculations have shown that hydroxylated (111) surfaces are more stable than clean (100) surfaces, ${ }^{37}$ with experimental and theoretical investigation providing a hydroxylated surface energy hierarchy of $\gamma_{(\mathrm{(11})}<\gamma_{(100)}<\gamma_{(110)} \cdot{ }^{38}$

Returning to carbon capture, $\mathrm{CO}_{2}$ adsorption on metal oxides is largely facilitated by low-coordination $\mathrm{O}^{2-}$ sites ${ }^{39-42}$ the acidic $\mathrm{CO}_{2}$ molecule reacts with a basic $\mathrm{O}^{2-}$ site. On predominant $\mathrm{MgO}$ (100) facets, $\mathrm{CO}_{2}$ adsorption will not occur, ${ }^{42,43}$ instead favouring corner and edge sites. DFT calculations have shown that the (111) facet of $\mathrm{CaO}$ is responsible for carbonate nucleation. ${ }^{44}$ Synthesis methods, ${ }^{30,45-47}$ and examples of catalytic application are present in the literature for (111) metal oxides. ${ }^{34,48,49}$ Considering favourable surface chemistry, we postulated that a (111) faceted adsorbent would be promising for carbon capture. Such a sorbent should possess: 1) enhanced reactivity towards $\mathrm{CO}_{2}$ (increased basicity of the polar $\mathrm{O}^{2-}$ sites); 2) enhanced capacity for $\mathrm{CO}_{2}$ (doubled population of exposed $\mathrm{O}^{2-}$ compared to a (100) facet) and 3) unique $\mathrm{CO}_{2}$ adsorption phenomena related to the (111) facet following high temperature treatment (removal of the stabilising hydroxylated surface layer to expose $\mathrm{O}^{2-}$ ).

Herein, we show that at sintering conditions found in practical application $\left(800^{\circ} \mathrm{C}\right), \mathrm{MgO}(111)$ nanosheets experience $\mathrm{a} \approx 30 \%$ reduction in surface area due to sintering, yet provide $\mathrm{a} \approx 65 \%$ increase in $\mathrm{CO}_{2}$ capacity (o.77 mmol $\left.\mathrm{g}^{-1} @ 227 \mathrm{~m}^{2} \mathrm{~g}^{-1} \mathrm{vs} 1.28 \mathrm{mmol} \mathrm{g}^{-1} @ 154 \mathrm{~m}^{2} \mathrm{~g}^{-1}\right)$. We compare $\mathrm{MgO}(111)$ nanosheets with commercial $\mathrm{MgO}$, conventionally prepared nanoparticle $\mathrm{MgO}$ (nano-MgO), and $\mathrm{MgO}(111)$ treated at $800^{\circ} \mathrm{C}$ to unambiguously attribute the enhanced capacity to the presence of the cleaned (111) facet. Furthermore, we show experimentally and theoretically that the high temperature treatment removes specific surface hydroxyl groups, providing insight into a new structure-activity relationship leading to enhanced capacity. The article is structured in three parts: 1) the impact of high temperature treatment on the physical properties of $\mathrm{MgO}(111) ; 2$ ) the subsequent paradoxical effect on $\mathrm{CO}_{2}$ adsorption capacity and 3) the surface chemistry changes facilitating the enhanced capacity. Throughout, $\mathrm{MgO}(111)$ refers to the as prepared sample pre-treated at $400^{\circ} \mathrm{C}$ (below the temperature of calcination during synthesis) and $\mathrm{MgO}(111) 800^{\circ} \mathrm{C}$ refers to the as prepared sample pretreated at $800^{\circ} \mathrm{C}$.

\section{Results}

\subsection{Adsorbent Characterisation}

$\mathrm{MgO}(111)$ and $\mathrm{MgO}(111) 800^{\circ} \mathrm{C}$ were identified as periclase $\mathrm{MgO}$ in the Inorganic Crystal Structure Database (ICSD PDF o1-071-1176) (Figure 1b). Sharpening of the $\mathrm{MgO}(111) 800^{\circ} \mathrm{C}$ diffractogram indicated crystallite size growth (Scherrer average crystallite size increase from 5.3 to $8.5 \mathrm{~nm}$ ). Bright-field transmission electron microscopy (BF-TEM) showed that $\mathrm{MgO}(111)$ was composed of platelike nanosheets within a size range of $5-25 \mathrm{~nm}$ (Figure 1c). After treatment at $800^{\circ} \mathrm{C}$ in-vacuo for $2 \mathrm{~h}$, morphology remained consistent, with growth of nanosheet size range to $15-30 \mathrm{~nm}$ (Figure 1c).

Scanning TEM (STEM) imaging and energy dispersive spectroscopy (EDS) further showed that both morphology and compositional homogeneity remained consistent after heat treatment (Figure $\mathrm{S} 1$ ). Nitrogen adsorptiondesorption confirmed the morphology observation, with $\mathrm{H}_{3}$ hysteresis loops present in all Type IV isotherms, indicative of
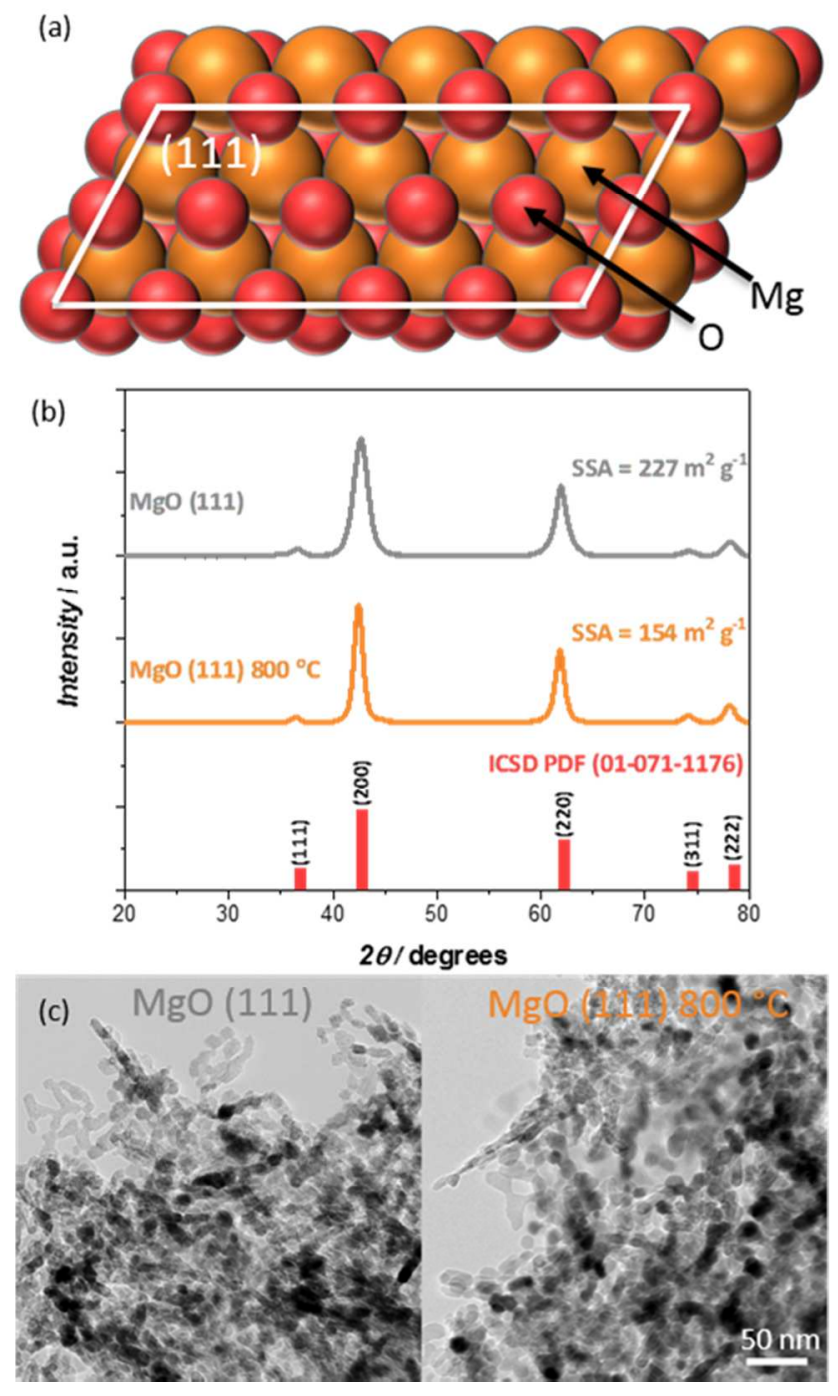

Figure 1. Structure and morphology of $\mathrm{MgO}(111)$ nanosheets. (a) Top view configuration of a $6 \times 3$ O-terminated $\mathrm{MgO}(111)$ surface; (b) phase identification by XRD for $\mathrm{MgO}(111)$ and $\mathrm{MgO}(111) 800^{\circ} \mathrm{C}$ with specific 
surface area inset; (c) BF-TEM images of $\mathrm{MgO}(111)$ and $\mathrm{MgO}(111)$ $800^{\circ} \mathrm{C}$.

aggregates of plate-like crystallites with intraparticle mesoporosity (Figure S2a)..$^{50}$ The major effect of treatment at $800^{\circ} \mathrm{C}$ was $\mathrm{a} \approx 30 \%$ reduction in surface area from 227 to $154 \mathrm{~m}^{2} \mathrm{~g}^{-1}$, with little impact on the mesoporous pore size distribution (Figure $\mathrm{ib}$ and $\mathrm{S} 2$ ). Taken together, the diffraction, microscopy, and $\mathrm{N}_{2}$ adsorption-desorption clearly evidenced a degree of sintering in $\mathrm{MgO}(111)$ after treatment at $800^{\circ} \mathrm{C}$.

\subsection{Sintering and $\mathrm{CO}_{2}$ Adsorption Capacity}

It is generally recognised that sintering of an adsorbent material results in reduction of adsorption capacity, in terms of saturated gas uptake. Examples include linear correlations between $\mathrm{H}_{2}$ gravimetric density and surface area of carbon aerogels, ${ }^{51}$ as well as $\mathrm{CO}_{2}$ uptake and surface area of MOFs and carbons. ${ }^{52,53}$ One would therefore expect a significant reduction in the $\mathrm{CO}_{2}$ capacity of the sintered $\mathrm{MgO} 800^{\circ} \mathrm{C}$ nanosheets, considering the $\approx 30 \%$ reduction in surface area from 227 to $154 \mathrm{~m}^{2} \mathrm{~g}^{-1}$ (Figure S2a). However, $\mathrm{a} \approx 65 \%$ increase in $\mathrm{CO}_{2}$ adsorption capacity was observed (Figure 2), from 0.77 to $1.28 \mathrm{mmol} \mathrm{g}^{-1}$, indicating increased utility of the surface capacity of $\mathrm{MgO}$. It is prudent to point out that carbonate formation on $\mathrm{MgO}$ is largely limited to the surface, particularly at low temperature $\left(T_{\mathrm{ads}}=35^{\circ} \mathrm{C}\right.$ ). ${ }^{54,55} \mathrm{Commercial} \mathrm{MgO}$ (SSA $=7 \mathrm{~m}^{2} \mathrm{~g}^{-1}$ ) and conventionally prepared nano-MgO (SSA = $84 \mathrm{~m}^{2} \mathrm{~g}^{-1}$ ) (Figure S2b) were compared with $\mathrm{MgO}(111)$, to investigate the link between increased capacity and presence of the (111) facet (Figure $\mathrm{S}_{3 \mathrm{C}}$ and d). $\mathrm{MgO}(111) 800^{\circ} \mathrm{C}$ gave the highest adsorption capacity of all samples (Figure $\mathrm{S}_{3} \mathrm{~b}$ ), two orders of magnitude higher than commercial $\mathrm{MgO}$. A simple explanation of increased physisorption to explain the increased capacity of $\mathrm{MgO}(111)$ after sintering is not possible due to the reduction in surface area. The full set of isotherms for all samples are provided, including adsorption at elevated temperature $\left(T_{\mathrm{ads}}=\right.$ $35-400^{\circ} \mathrm{C}$ ) (Figure $\left.\mathrm{S}_{3}\right)$.

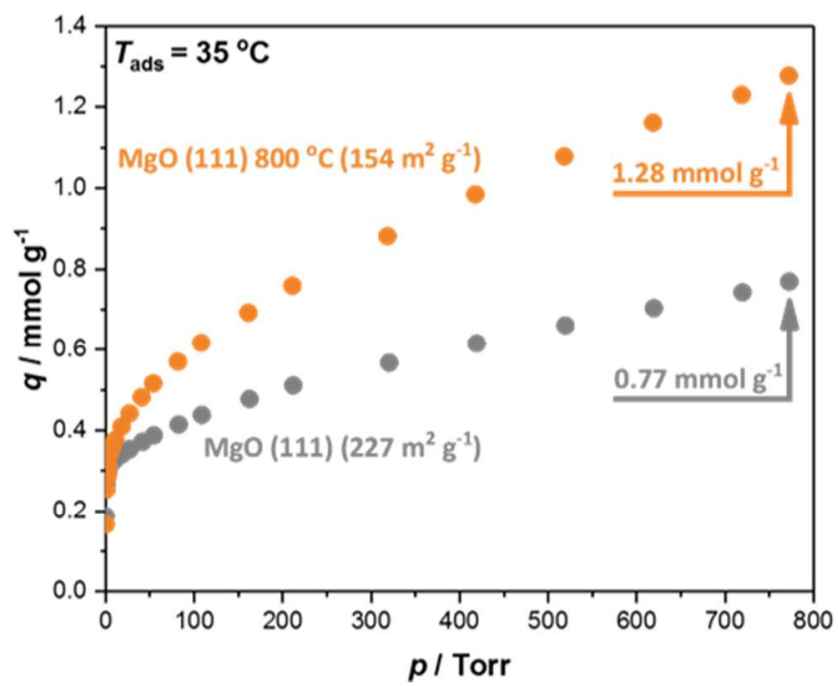

Figure 2. $\mathrm{CO}_{2}$ adsorption isotherms $\left(T_{\mathrm{ads}}=35{ }^{\circ} \mathrm{C}\right)$ on $\mathrm{MgO}(111)$ and $\mathrm{MgO}(111) 800^{\circ} \mathrm{C}$ with specific surface areas inset. Lower surface area conversely provides higher $\mathrm{CO}_{2}$ uptake.
2.3 Surface Chemistry and Structure-Activity Relationship

Considering the paradoxical impact of sintering $\mathrm{MgO}(111)$ on $\mathrm{CO}_{2}$ adsorption capacity, the surface chemistry of $\mathrm{MgO}(111)$ was investigated before and after sintering. Diffuse-reflectance infrared spectroscopy (DRIFTS) evidenced two "free" surface hydroxyl vibrational modes at 3760 and $3723 \mathrm{~cm}^{-1}$ amongst a range of hydrogenbonded hydroxyl groups (ca. $3650-3300 \mathrm{~cm}^{-1}$ ) (Figure 3a). ${ }^{56,57}$ Following treatment at $800^{\circ} \mathrm{C}$ in-vacuo for $2 \mathrm{~h}$, a slight reduction in intensity of the band at 3760 was apparent, with the mode at $3723 \mathrm{~cm}^{-1}$ significantly reduced in intensity. Surface dehydration of the O-terminated (111) surface would leave behind the necessary low-coordinate $\mathrm{O}^{2-}$ sites required for $\mathrm{CO}_{2}$ adsorption, as well as $\mathrm{Mg}^{2+}$ exposed by $\mathrm{O}$ vacancies.

Density functional theory (DFT) calculations were performed to elucidate the nature of the experimentally observed peaks at 3760 and $3723 \mathrm{~cm}^{-1}$. A range of adsorbates were investigated, water and $\mathrm{H}$ (of the $\mathrm{OH}$ group), on $\mathrm{O}$ and $\mathrm{Mg}$-terminated $\mathrm{MgO}(111)$ surfaces, with a selection of surface coverage variations (Figure $\mathrm{S}_{4}$ ). A 100\% H-covered $\mathrm{O}$-terminated surface gave a calculated $\mathrm{OH}$ stretch mode frequency of $3764 \mathrm{~cm}^{-1}$, sufficiently close to the experimental value so as to confirm the $376 \mathrm{~cm}^{-1}$ band belonged to an $\mathrm{OH}$ stretching mode on such a surface (Figure 3a). A $100 \% \mathrm{H}$-covered, O-terminated surface has been shown computationally and experimentally to be extremely stable. ${ }^{58,59}$ Other simulated (111) surfaces (Figure S4a-d), as well as a small selection of $\mathrm{MgO}$ (110) and $\mathrm{MgO}$ (10o) surfaces (not shown), could not be assigned to the remaining $3723 \mathrm{~cm}^{-1}$ band as a result of large frequency mismatch. These large differences were due to significant structural modifications such as the presence of water, or bonding to $\mathrm{Mg}^{2+}$ sites in place of $\mathrm{O}^{2-}$ sites. However, modifying the $100 \% \mathrm{H}$-covered O-terminated surface to remove every second row of $\mathrm{OH}$ groups, i.e. 50\% $\mathrm{H}$ covered, O-terminated surface (Figure $\mathrm{S}_{4} \mathrm{e}$ ), gave a frequency band between 3733 and $3725 \mathrm{~cm}^{-1}$. This indicated that the $3723 \mathrm{~cm}^{-1}$ band was likely due to portions of the O-terminated surface not $100 \%$ covered with hydrogen (Figure 3a). Sintering at $800^{\circ} \mathrm{C}$ removed hydrogen to reveal $\mathrm{O}^{2-}$ sites suitable for $\mathrm{CO}_{2}$ adsorption, likely via condensation which would also reveal subsurface $\mathrm{Mg}^{2+}$. Considered together with the DFT calculations (Figure $\mathrm{S}_{4}$ ), the major surface activation was the removal of hydroxyl groups from a partially covered (111) surface $\left(3723 \mathrm{~cm}^{-1}\right)$. This would be logical considering the stability of the fully hydroxylated O-terminated surface. ${ }^{58,59} \mathrm{~A}$ more intricate dependence of the $\mathrm{OH}$ stretch mode frequency on $\mathrm{H}$ coverage may well exist, with alternative explanations including hydrogen bonding of the $3760 \mathrm{~cm}^{-1}$ hydroxyl and lower index defects and edge planes. ${ }^{60}$ The loss of the $3723 \mathrm{~cm}^{-1}$ peak indicated that it was strongly involved in changes to the surface upon sintering.

Further evidence for the creation of new basic $\mathrm{O}^{2-}$ sites on the (111) surface after treatment at $800^{\circ} \mathrm{C}$ was provided by temperature programmed desorption of $\mathrm{CO}_{2}\left(\mathrm{CO}_{2}-\right.$ 
TPD) (Figure 3b). Briefly, $\mathrm{MgO}(111)$ was treated in flowing
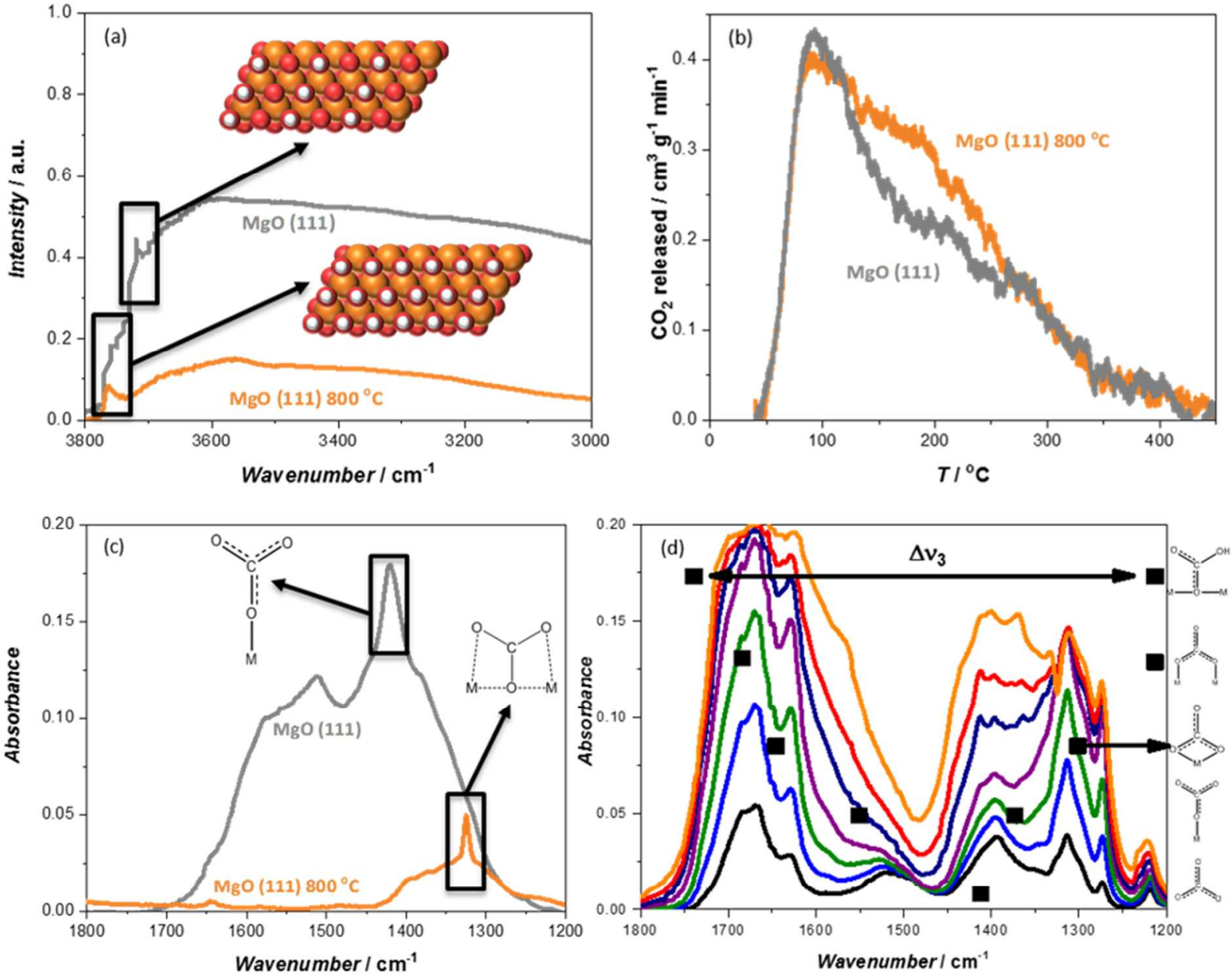

Figure 3. Surface chemistry investigation of $\mathrm{MgO}(111)$. (a) DRIFTS spectra of $\mathrm{MgO}(111)$ and $\mathrm{MgO}(111) 800^{\circ} \mathrm{C}$ evidencing surface hydroxyl removal, DFT simulated surfaces inset used to calculate hydroxyl stretch frequencies (Figure $\mathrm{S}_{4}$ ); (b) $\mathrm{CO}_{2}-\mathrm{TPD}$ of $\mathrm{MgO}(111)$ and $\mathrm{MgO}(111) 800^{\circ} \mathrm{C}$ evidencing creation of new intermediate basicity sites due to surface hydroxyl removal; (c) in-situ transmission FTIR spectra of MgO(111) and MgO(111) $800^{\circ} \mathrm{C}$ of residual carbonates following thermal pre-treatment; (d) in-situ transmission FTIR spectra of $\mathrm{MgO}(111) 800^{\circ} \mathrm{C}$ following exposure of increasing pressures of $\mathrm{CO}_{2}$, band growth in the $1800-1200 \mathrm{~cm}-1$ region evidencing formation of a variety of carbonates. Right hand axis displays different carbonate structures assignable on the basis of asymmetric stretching mode ( $v_{3}$ ) splitting.

400 and $800^{\circ} \mathrm{C}$ for $2 \mathrm{~h}$ before exposure to $\mathrm{CO}_{2}$ and subsequent temperature programmed desorption. During temperature ramping from 50 to $400^{\circ} \mathrm{C}, \mathrm{CO}_{2}$ was evolved in a similar manner for both 400 and $800^{\circ} \mathrm{C}$ treated samples (Figure $3 \mathrm{~b})$. Weak $\left(T_{\mathrm{d}}<120^{\circ} \mathrm{C}\right)$ and strong $\left(T_{\mathrm{d}}>\right.$ $275^{\circ} \mathrm{C}$ ) basic site densities were similar after both treatments (Table $\mathrm{S} 1)$. In the intermediate strength range $\left(T_{\mathrm{d}}=\right.$ $\left.120-275^{\circ} \mathrm{C}\right) \mathrm{a} \approx 30 \%$ increase was observed after treatment at $800^{\circ} \mathrm{C}$, due to the removal of hydroxyl functionality evidenced previously (Figure 3a). $\mathrm{MgO}(111)$ will present a large population of intermediate basicity sites, due to the unique structure; ${ }^{61}$ treating at high temperature increases this population further. Hydroxyl functionality on $\mathrm{MgO}$ powders has previously been shown to be stable to $500^{\circ} \mathrm{C}$. ${ }^{56,57}$ Therefore, sintering at $800^{\circ} \mathrm{C}$ explores a new temperature region and results in the removal of further hydroxyl functionality, creating further sites for $\mathrm{CO}_{2}$ adsorption. After sintering, the total number of basic sites increased from 357 to $415 \mu \mathrm{mol} \mathrm{g}{ }^{-1}$ assuming a stoichiometry of one basic site per $\mathrm{CO}_{2}$ molecule. As will be shown later, this assumption gives a relative indication of basic site density, with any true evaluation dependant on car- bonate coordination - far from trivial on $\mathrm{MgO}(111)$ (Figure 3d). Total $\mathrm{CO}_{2}$ uptake closely matched that of the equilibrated isotherm at the $\mathrm{CO}_{2}$ partial pressure used during TPD dosing (ca. 65 Torr).

Regarding the presence and formation of carbonates on the $\mathrm{MgO}(111)$ surface, significant differences following $2 \mathrm{~h}$ treatment at 400 and $800^{\circ} \mathrm{C}$ in-vacuo were observed by in-situ transmission FTIR spectroscopy (Figure 3c and d). Absorption bands due to carbonate species were observed in the $1800-1200 \mathrm{~cm}^{-1}$ region following both treatments, yet the intensity decrease in the carbonate region was more pronounced following $800^{\circ} \mathrm{C}$ treatment (Figure 3c). A simple argument for increased capacity would be that removal of more carbonate species at $800^{\circ} \mathrm{C}$ provides additional capacity for $\mathrm{CO}_{2}$. However, as surface area was reduced by $\approx 30 \%$ yet capacity increased by $\approx$ $65 \%$, a further explanation is required i.e. the aforementioned creation of $\mathrm{O}^{2-}$ and $\mathrm{Mg}^{2+}$ sites following sintering (Figure 3a). After treatment at $400^{\circ} \mathrm{C}$, a prominent feature at $1420 \mathrm{~cm}^{-1}$ indicated the presence of monodentate carbonates on the (111) surface. ${ }^{62}$ A maximum at $1512 \mathrm{~cm}^{-1}$ and 
weaker features/shoulders at 1650, 1590, and $1380 \mathrm{~cm}^{-1}$ indicated that a range of carbonate species remained on the surface. ${ }^{63}$ These features were further evidence of the presence of the (111) surface contributing to $\mathrm{CO}_{2}$ adsorption, as on well-defined (10o) facets, absorption in the $1600-1350 \mathrm{~cm}^{-1}$ range was not observed. ${ }^{64}$ Following treatment at $800^{\circ} \mathrm{C}$, a uniquely sharp feature at $1325 \mathrm{~cm}^{-1}$ and a weak feature at $1645 \mathrm{~cm}^{-1}$ were assigned as tridentate carbonate species on the (111) surface facilitated by surface defects, either $\mathrm{O}^{2-}$ vacancies to expose subsurface $\mathrm{Mg}^{2+}$, or at edges. ${ }^{62}$ Weak absorption at 1580 and $1400-$ $1300 \mathrm{~cm}^{-1}$ indicated the presence of bidentate and monodentate carbonates. ${ }^{6_{3}}$ Upon exposure of $\mathrm{CO}_{2}$ to $\mathrm{MgO}(111)$ after treatment at $800^{\circ} \mathrm{C}$, a range of carbonate species were formed, identifiable on the basis of the splitting of the $v_{3}$ asymmetric stretching mode (Figure $3 \mathrm{~d}$ ). ${ }^{63}$ A variety of monodentate and bidentate carbonate species were identified, as well as bicarbonates formed in the presence of remaining surface hydroxyl groups as we have observed previously in related systems. ${ }^{65,66}$ In agreement with decreasing $\mathrm{CO}_{2}$ capacity at increased temperature observed in $\mathrm{CO}_{2}$ adsorption isotherms (Figure $\mathrm{S}_{3}$ ), an absorption maximum at $2345 \mathrm{~cm}^{-1}$ indicative of physisorbed $\mathrm{CO}_{2}$ was present throughout (not shown). The complexity of carbonate speciation highlights the convoluted nature of the $\mathrm{CO}_{2}$-TPD basic site quantification, i.e. assuming a stoichiometry of one binding site per $\mathrm{CO}_{2}$ molecule is incorrect.

\subsection{Impact of the (111) Facet in Carbon Capture Pro- cesses}

Clearly, the expected impact of surface area reduction on surface adsorption capacity is more complex than a simple linear relationship. The presence of the (111) facet overcame the significant reduction in surface area, facilitated by the removal of specific hydroxyl groups from the surface; wider impacts of these findings are briefly discussed. Firstly, in calcium looping, rehydration is a common strategy to enhance sorbent utility. ${ }^{16}$ Steam hydration of $\mathrm{CaO}$ (as opposed to hydration of $\mathrm{CaCO}_{3}$ ) is favoured for regenerating spent sorbent. ${ }^{67}$ Current interpretations of the positive impact of hydration involve the creation of new surface area and porosity, through rupturing of $\mathrm{CaO}$ particles upon hydration due to the larger specific volume of $\mathrm{Ca}(\mathrm{OH})_{2}$. Consider that hydration stabilises the (111) facet of rock salt oxides, ${ }^{34-36}$ and that this hydrated sorbent enters a high temperature carbonating reactor. Taken with our findings, we suggest that faceting plays a unique role in enabling the formation and retention of highly active $\mathrm{CO}_{2}$ adsorption sites during hydration, despite overall loss of surface area. Furthermore, it is worth noting that so-called "double salt" carbon capture sorbents (a metal oxide with molten salt on the surface), ${ }^{68-70}$ and dual phase molten salt-ceramic membranes, [68] may inadvertently experience similar faceting effects to those noted here. Strong electrostatic interactions between molten salt ions and solid metal oxide surfaces significantly lower the surface energy of polar facets. ${ }^{45}$ As a result, polar faceting in these sorbents and devices may well occur, contributing to interfacial phenomena.

\section{Conclusions}

An approach routinely applied in catalysis - synthetic control over crystalline facets - produced a sorbent for carbon capture with high capacity. This activity was due to the preferential exposure of the polar (111) facet and the surface exposed after thermal treatment. $\mathrm{MgO}(111)$ nanosheets displayed $\mathrm{a} \approx 65 \%$ increase in $\mathrm{CO}_{2}$ adsorption capacity following sintering at $800^{\circ} \mathrm{C}$. This was unexpected as the treatment also resulted in $\mathrm{a} \approx 30 \%$ reduction in surface area. Further interrogation through spectroscopy and theory demonstrated that removal of hydroxyl functionality from the (111) facet exposes and retains low coordinate $\mathrm{O}^{2-}$ and $\mathrm{Mg}^{2+}$ sites, facilitating enhanced capacity.

Of consideration for all carbon capture processes, is the cost of sorbent manufacture. Although our synthesised (111) sorbent shows promising capacity, we suggest that the most important practical conclusion is that the addition of steam in looping cycles to stabilise the (111) facet and subsequent high temperature activation may well enhance capacity in existing affordable adsorbents. To be clear, we wish to highlight that control of specific facets through activation procedures easily integrated with existing pilot-scale carbon capture processes (e.g. calcium looping) is of primary significance.

In summary, we challenge the assumption that sintering is necessarily a negative process in high temperature "looping" cycles for $\mathrm{CO}_{2}$ adsorption; the high temperature conditions can be leveraged for facet-dependent surface activation. In this case, we have shown that the presence of specific facets can be more important than the total surface area lost during sintering. We provide the first example of a faceted sorbent (of specified morphology) for carbon capture and give insight into new structureactivity relationships in materials relevant for environmental processes.

\section{Materials and Methods}

\subsection{Adsorbent Synthesis}

$\mathrm{MgO}(111)$ nanosheets were prepared following a modified aero-gel methodology. ${ }^{46}$ Magnesium belt (Mg) (Sigma-Aldrich, 99.5\%) was roughened with sandpaper and cleaned with acetone (Pharmco-Aaper, 99.5\%). The roughened magnesium was cut into small portions and dissolved in anhydrous methanol (Avantor, 99.9\%) under nitrogen (Praxair, > 99.5\%). Once dissolved, 4-methoxylbenzyl alcohol (BZ) (Sigma-Aldrich, 98\%) was added (molar ratio 2:1, Mg:BZ) and stirred for $5 \mathrm{~h}$. Water in methanol was added (molar ratio 2:1, $\mathrm{H}_{2} \mathrm{O}: \mathrm{Mg}$, $30.0 \mathrm{~mL}$ $\mathrm{MeOH}$ ) dropwise with stirring. After $12 \mathrm{~h}$ of stirring the mixture was transferred to an autoclave, purged and then pressurised to 10 bar with argon (Praxair, > 99.998\%). The mixture was heated at $265^{\circ} \mathrm{C}$ for $15 \mathrm{~h}$, followed by venting of the supercritical solvent. The collected powder was calcined at $500^{\circ} \mathrm{C}$ in air for $6 \mathrm{~h}$. Commercial MgO (SigmaAldrich, 98\%) and conventionally prepared nano-MgO (NanoScale Corporation, NanoActive $\mathrm{MgO} \geq 95 \%$ ) were used as received. 


\subsection{Adsorbent Characterisation}

Surface area and porosity analyses were conducted using a Micromeritics Tristar with $\mathrm{N}_{2}$ as adsorbate. Powdered samples were treated at $200^{\circ} \mathrm{C}$ for $3 \mathrm{~h}$ in flowing $\mathrm{N}_{2}$. Adsorption-desorption was performed at $-196^{\circ} \mathrm{C}$, with the Brunauer-Emmett-Teller (BET) method applied to determine surface area and the Barrett-Joyner-Halenda (BJH) method used to determine pore volume and pore size distribution.

X-ray diffraction (XRD) data were collected with an Empyrean diffractometer (PANalytical, NL) using $\mathrm{Cu}-\mathrm{K} \alpha$ radiation $(\lambda=1.54 \AA$ ). Powdered samples (ca. $0.2 \mathrm{~g}$ ) were supported in aluminium holders after loose packing. Patterns were collected from $10-80^{\circ} 2 \theta$ with a step size of $0.026^{\circ}$ and a total collection time of 20 minutes. Scherrer crystallite size analysis was performed on the (200) $\mathrm{MgO}$ periclase peak.

Transmission electron microscopy characterisation was conducted using an FEI Co. Talos F20oX with a FEI X-FEG high brightness electron source operating at an accelerating voltage of $200 \mathrm{kV}$. Samples were prepared as an ultrasonic suspension in ethanol spread on a carbon coated copper grid. Bright-field (BF-TEM), scanning (STEM) and energy dispersive spectroscopy (EDS) modes were utilised.

\section{3 $\mathrm{CO}_{2}$ Adsorption}

$\mathrm{CO}_{2}$ adsorption isotherms were measured with a Micromeritics ASAP 2020C. Powdered samples were loaded into a quartz tube, surrounded by loosely packed plugs of quartz wool. Manual and automatic leak checks were conducted upon sample loading and immediately before adsorption isotherm collection respectively. $\mathrm{CO}_{2}$ (BOC, 99.8\%) was connected to the apparatus through a moisture trap (Alltech Hydro-Purge) filled with freshly conditioned adsorbent (Molecular Sieve 3A, Fischer Scientific). Sequenced experiments were run to obtain isotherms at $35,100,200,300$ and $400^{\circ} \mathrm{C}$ with initial and intermittent 400 and $800^{\circ} \mathrm{C}$ high temperature treatments (i.e. below and above the calcination temperature of synthesised sorbents).

\subsection{Surface Chemistry and Structure-Activity Relation- ship}

Diffuse reflectance infrared spectroscopy (DRIFTS) was conducted using a Thermo Nicolet 4700 IR spectrometer fitted with a liquid nitrogen cooled detector and DRIFTS accessory. $\mathrm{KBr}$ under vacuum $\left(<3 \times 10^{-2} \mathrm{Torr}\right)$ at room temperature was used as a background for all spectra. $\mathrm{MgO}(111)$ was heated to $400^{\circ} \mathrm{C}$, held for 15 minutes, then heated to $800^{\circ} \mathrm{C}$ and held for $2 \mathrm{~h}$. All ramp rates were $10^{\circ} \mathrm{C}$ $\min ^{-1}$. The sample was then cooled to room temperature before spectral acquisition. The complete procedure was under vacuum. Spectra were collected as an accumulation of 120 scans over a range of $4000-600 \mathrm{~cm}^{-1}$ at a resolution of $4 \mathrm{~cm}^{-1}$.

$\mathrm{CO}_{2}$ temperature-programmed desorption $\left(\mathrm{CO}_{2}-\mathrm{TPD}\right)$ was performed in a Micromeritics AutoChem II 2920 chemisorption instrument. Samples were treated in situ with a $10^{\circ} \mathrm{C} \min ^{-1}$ ramp under flowing He (UHP, 99.999\%) to a final temperature of 400 or $800^{\circ} \mathrm{C}$ and held for $2 \mathrm{~h}$ before being cooled to $40^{\circ} \mathrm{C}$ under flowing He. The samples were dosed with a $10 \% \mathrm{CO}_{2} / \mathrm{He}$ blend for $1.5 \mathrm{~h}$, and purged with $\mathrm{He}$ for $1 \mathrm{~h}$ to remove physisorbed $\mathrm{CO}_{2}$. The thermal desorption of chemisorbed $\mathrm{CO}_{2}$ was then performed in flowing He at a ramp rate of $10^{\circ} \mathrm{C} \min ^{-1}$ to a final temperature of $800^{\circ} \mathrm{C}$ while the evolved $\mathrm{CO}_{2}$ was quantified by changes in downstream thermal conductivity. Blank He-TPD experiments were performed on both samples to remove baseline differences between pretreatment temperatures due to desorbing water. All flow rates were $50 \mathrm{~mL} \mathrm{~min}^{-1}$. Sample basicities are reported on a dry sample mass basis with an assumed stoichiometry of one basic site per $\mathrm{CO}_{2}$ molecule (the appropriateness of which is discussed in the manuscript).

In-situ Fourier Transform Infrared Spectroscopy (FTIR) was performed using a PerkinElmer Spectrum 100 spectrometer. Powdered samples (ca. $20 \mathrm{mg}$ ) were pressed (Specac 15.011 Manual Hydraulic Press) at 1 - 3 tons into self-supporting discs of $13 \mathrm{~mm}$ diameter. Sample discs were suspended in a custom-made quartz holder and loaded into a high vacuum glass line apparatus, fitted with a high temperature furnace $\left(T_{\max }=1000^{\circ} \mathrm{C}\right)$. Sample discs were treated at 400 or $800^{\circ} \mathrm{C}$ under high vacuum (< $3.75 \times 10^{-6}$ Torr) for $2 \mathrm{~h}$. A $23 \% \mathrm{CO}_{2}$ mixture (balance $\mathrm{N}_{2}$ ) was used to fill a glass bulb which was attached to the vacuum apparatus. Following high temperature treatment, samples were cooled to room temperature under high vacuum before exposure to increasing pressures of $\mathrm{CO}_{2}$. Spectra were collected as an accumulation of 25 scans over a range of $4000-1000 \mathrm{~cm}^{-1}$ at a resolution of 4 $\mathrm{cm}^{-1}$ with automated atmospheric background subtraction. Experimental spectra were subtracted from the initial spectrum collected immediately following pretreatment. In this way, changes to spectral features are only related to differences in the sample following $\mathrm{CO}_{2}$ exposure.

DFT calculations were performed using the generalised gradient approximation (GGA) with the revised PerdewBurke-Ernzerhof ${ }^{72,73}$ functional and the plane-waves code VASP. ${ }^{74,75}$ Adsorbates on the surface were relaxed via conjugate-gradient in the presence of dipole corrections using a plane-wave cut-off of $500 \mathrm{eV}$, a $6 \times 3$ surface cell, and Monkhorst-Pack $k$-point grid of $3 \times 3 \times 1$ for sampling the Brillouin zone. Once residual forces on all ions had decreased below $0.005 \mathrm{eV} / \AA$, relaxations were stopped and frequency calculations were performed. Several adsorbates, water and $\mathrm{H}$ (of the $\mathrm{OH}$ group), on both $\mathrm{O}$ - and $\mathrm{Mg}$ terminated (111) surfaces were tested.

\section{ASSOCIATED CONTENT}

Supporting Information. Synthesis procedure, experimental methods, computational methods, transmission microscopy images, $\mathrm{N}_{2}$ adsorption-desorption isotherms and pore size distributions, additional $\mathrm{CO}_{2}$ adsorption isotherms and density functional theory model surfaces. This material is available free of charge via the Internet at http://pubs.acs.org. 


\section{AUTHOR INFORMATION}

\section{Corresponding Author}

*gregamutch@gmail.com

\section{Author Contributions}

All authors have given approval to the final version of the manuscript.

Notes

The authors declare no competing financial interest.

\section{ACKNOWLEDGMENT}

This work was supported by the Engineering and Physical Sciences Research Council (EPSRC) via a Doctoral Training Grant for G.A.M. (EP/K0502960/1) and a Doctoral Prize Fellowship (EP/M50791X/1). Dedicated to the memory of Kenneth J. Klabunde.

\section{REFERENCES}

(1) Boot-Handford, M. E.; Abanades, J. C.; Anthony, E. J.; Blunt, M. J.; Brandani, S.; Mac Dowell, N.; Fernández, J. R.; Ferrari, M.-C.; Gross, R.; Hallett, J. P.; Haszeldine, R. S.; Heptonstall, P.; Lyngfelt, A.; Makuch, Z.; Mangano, E.; Porter, R. T. J.; Pourkashanian, M.; Rochelle, G. T.; Shah, N.; Yao, J. G.; Fennell, P. S. Energy Environ. Sci. 2014, 7 (1), 130.

(2) Sanz-Pérez, E. S.; Murdock, C. R.; Didas, S. A.; Jones, C. W. Chem. Rev. 2016, 116, 11840.

(3) Bhatt, P. M.; Belmabkhout, Y.; Cadiau, A.; Adil, K.; Shekhah, O.; Shkurenko, A.; Barbour, L. J.; Eddaoudi, M. J. Am. Chem. Soc. 2016, 138 (29), 9301-9307.

(4) McDonald, T. M.; Lee, W. R.; Mason, J. A.; Wiers, B. M.; Hong, C. S.; Long, J. R. J. Am. Chem. Soc. 2012, 134 (16), 7056-7065.

(5) Zhao, X.; Zhou, H.; Sikarwar, V. S.; Zhao, M.; Park, A.-H. A. Fennell, P. S.; Shen, L.; Fan, L.-S. Energy Environ. Sci. 2017, 10, 1885 .

(6) Bui, M.; Fajardy, M.; Mac Dowell, N. Appl. Energy 2017, 195, 289.

(7) Rubin, E. S.; Davison, J. E.; Herzog, H. J. Int. J. Greenh. Gas Control 2015, 40, 378.

(8) Singh, P.; Rheinhardt, J. H.; Olson, J. Z.; Tarakeshwar, P.; Mujica, V.; Buttry, D. A. J. Am. Chem. Soc. 2017, 139 (3), 1033-1036.

(9) Benson, S. M.; Cole, D. R. Elements 2008, 4 (5), 325

(10) Nandi, S.; Collins, S.; Chakraborty, D.; Banerjee, D.; Thallapally, P. K.; Woo, T. K.; Vaidhyanathan, R. J. Am. Chem. Soc. 2017, 139 (5), 1734-1737.

(11) Bates, E. D.; Mayton, R. D.; Ntai, I.; Davis, J. H. J. Am. Chem. Soc. 2002, 124 (6), 926-927.

(12) Kim, T. K.; Lee, K. J.; Cheon, J. Y.; Lee, J. H.; Joo, S. H.; Moon, H. R. J. Am. Chem. Soc. 2013, 135 (24), 8940-8946.

(13) Hicks, J. C.; Drese, J. H.; Fauth, D. J.; Gray, M. L.; Qi, G.; Jones, C. W. J. Am. Chem. Soc. 2008, 130 (10), 2902-2903.

(14) Adanez, J.; Abad, A.; Garcia-Labiano, F.; Gayan, P.; De Diego, L. F. Prog. Energy Combust. Sci. 2012, 38 (2), 215.

(15) Hufton, J. R.; Mayorga, S.; Sircar, S. AIChE J. 1999, 45 (2), 248.

(16) Blamey, J.; Anthony, E. J.; Wang, J.; Fennell, P. S. Prog. Energy Combust. Sci. 2010, 36 (2), 260.

(17) Erans, M.; Manovic, V.; Anthony, E. J. Appl. Energy 2016, 180, 722.

(18) Zhao, M.; Shi, J.; Zhong, X.; Tian, S.; Blamey, J.; Jiang, J.; Fennell, P. S. Energy Environ. Sci. 2014, 7, 3291.

(19) Broda, M.; Müller, C. R. Adv. Mater. 2012, 24 (22), 3059.

(20) Liu, W.; Feng, B.; Wu, Y.; Wang, G.; Barry, J.; da Costa, J. C. D. Environ. Sci. Technol. 2010, 44 (8), 3093.

(21) Mutch, G. A.; Anderson, J. A.; Vega-Maza, D. Appl. Energy 2017, 202, 365 .
Farha, O. K.; Eryazici, I.; Jeong, N. C.; Hauser, B. G.; Wilmer, C. E.; Sarjeant, A. a.; Snurr, R. Q.; Nguyen, S. T.; Yazaydin, A. O.; Hupp, J. T. J. Am. Chem. Soc. 2012, 134 (36), 15016.

(23) Farha, O. K.; YazaydınA., Ö.; Eryazici, I.; Malliakas, C. D.; Hauser, B. G.; Kanatzidis, M. G.; Nguyen, S. T.; Snurr, R. Q.; Hupp, J. T. Nat Chem 2010, 2 (11), 944

(24) Bian, S.-W.; Baltrusaitis, J.; Galhotra, P.; Grassian, V. H. J. Mater. Chem. 2010, 20 (39), 8705.

(25) Bhagiyalakshmi, M.; Lee, J. Y.; Jang, H. T. Int. J. Greenh. Gas Control 2010, $4,51$.

(26) Wang, S.; Yan, S.; Ma, X.; Gong, J. Energy Environ. Sci. 2011, 4 (10), 3805.

(27) Zhou, K.; Li, Y. Angew. Chemie - Int. Ed. 2012, 51 (3), 602.

(28) Pal, J.; Pal, T. Nanoscale 2015, 7 (34), 14159.

(29) Huang, W. Acc. Chem. Res. 2016, 49 (3), 520.

(30) Abdelhamid, A. A.; Yu, Y.; Yang, J.; Ying, J. Y. Adv. Mater. 2017, 1701427, 1701427.

(31) Finocchi, F.; Barbier, A.; Jupille, J.; Noguera, C. Phys. Rev. Lett. 2004, 92 (13), 136101-1.

(32) Goniakowski, J.; Finocchi, F.; Noguera, C. Reports Prog. Phys. 2007, 71 (1), 16501.

(33) Noguera, C.; Goniakowski, J. Chem. Rev. 2013, 113 (6), 4073.

(34) Cadigan, C. A.; Corpuz, A. R.; Lin, F.; Caskey, C. M.; Finch, K. B. H.; Wang, X.; Richards, R. M. Catal. Sci. Technol. 2013, 3 (4), 900.

(35) Hacquart, R.; Jupille, J. Chem. Phys. Lett. 2007, 439 (1-3), 91.

(36) Lee, M. H. Phys. Rev. B 1968, 52 (15), 10823.

(37) Wander, A.; Bush, I.; Harrison, N. Phys. Rev. B 2003, 68 (233405), 233405-1.

(38) Geysermans, P.; Finocchi, F.; Goniakowski, J.; Hacquart, R.; Jupille, J. Phys. Chem. Chem. Phys. 2009, 11 (100), 2228.

(39) Pacchioni, G. Surf. Sci. 1993, 281 (1-2), 207.

(40) Meixner, D. L.; Arthur, D. A.; George, S. M. Surf. Sci. 1992 $261,141$.

(41) Daub, C. D.; Patey, G. N.; Jack, D. B.; Sallabi, A. K. J. Chem. Phys. 2006, 124 (114706), 114706-1.

(42) Jensen, M. B.; Pettersson, L. G. M.; Swang, O.; Olsbye, U. J. Phys. Chem. B 2005, 109 (35), 16774.

(43) Karlsen, E. J.; Nygren, M. A.; Pettersson, L. G. M. J. Phys. Chem. B 2003, 107 (31), 7795.

(44) Besson, R.; Favergeon, L. J. Phys. Chem. C 2013, 117, 8813.

(45) Xu, T.; Zhou, X.; Jiang, Z.; Kuang, Q.; Xie, Z.; Zheng, L. Cryst. Growth Des. 2009, 9 (1), 192.

(46) Zhu, K.; Hu, J.; Kübel, C.; Richards, R. Angew. Chemie - Int. Ed. 2006, 45 (43), 7277.

(47) Hu, J.; Zhu, K.; Chen, L.; Yang, H.; Li, Z.; Suchopar, A.; Richards, R. Adv. Mater. 20o8, 20 (2), 267.

(48) Zhu, K.; Hua, W.; Deng, W.; Richards, R. M. Eur. J. Inorg. Chem. 2012, 2012 (17), 2869.

(49) Hu, J.; Zhu, K.; Chen, L.; Ku, C.; Richards, R. J. Phys. Chem. C 2007, 111, 12038.

(50) Sing, K. S. W.; Everett, D. H.; Haul, R. A. W.; Moscou, L.; Pierotti, R. A.; Rouquerol, J.; Siemieniewska, T. Pure Appl. Chem. 1985, 57 (4), 603.

(51) Kabbour, H.; Baumann, T. F.; Satcher, J. H.; Saulnier, A.; Ahn, C. C. Chem. Mater. 2006, 18 (26), 6085.

(52) Li, J.; Ma, Y.; Mccarthy, M. C.; Sculley, J.; Yu, J.; Jeong, H.; Balbuena, P. B.; Zhou, H.-C. Coord. Chem. Rev. 2011, 255 (15-16), 1791.

(53) Wang, L.; Yang, R. T. J. Phys. Chem. C 2012, 116, 1099.

(54) Gregg, S. J.; Ramsay, J. D. J. Chem. Soc. 1970, 1 (956), 2784.

(55) Prashar, A. K.; Seo, H.; Choi, W. C.; Kang, N. Y.; Park, S.; Kim, K.; Min, D. Y.; Kim, H. M.; Park, Y.-K. Energy E Fuels 2016, 30, 3298.

(56) Knozinger, E.; Jacob, K.-H.; Singh, S.; Hofmann, P. Surf. Sci. 1993, 290, 388.

(57) Coluccia, S.; Marchese, L.; Lavagnino, S.; Anpo, M. Spectrochim. Acta 1987, 43A, 1573.

(58) Ciston, J.; Subramanian, A.; Marks, L. D. arXiv 2008 https://arxiv.org/pdf/o8o9.2459. 
(59) Lazarov, V. K.; Plass, R.; Poon, H.; Saldin, D. K.; Weinert, M.; Chambers, S. A.; Gajdardziska-Josifovska, M. Phys. Rev. B 2005, 115434, 115434-1.

(6o) Ciston, J.; Subramanian, A.; Marks, L. D. Phys. Rev. B 2009, 79, $084521-084522$.

(61) Verziu, M.; Cojocaru, B.; Hu, J.; Richards, R.; Ciuculescu, C.; Filip, P.; Parvulescu, V. I. Green Chem. 2oo8, 10, 373.

(62) Cornu, D.; Guesmi, H.; Krafft, J.-M.; Lauron-Pernot, H. J. Phys. Chem. C 2012, 116, 6645.

(63) Busca, G.; Lorenzelli, V. Mater. Chem. 1982, 7 (1), 89.

(64) Yanagisawa, Y.; Takaoka, K.; Yamabe, S. J. Phys. Chem. 1995, 99, 3704.

(65) Mutch, G. A.; Morandi, S.; Walker, R.; Anderson, J. A.; Vega-Maza, D.; Operti, L.; Cerrato, G. J. Phys. Chem. C 2016, 120, 17570-17578.

(66) Mutch, G. A.; Anderson, J. A.; Walker, R.; Cerrato, G.; Morandi, S.; Operti, L.; Vega-Maza, D. Int. J. Greenh. Gas Control 2016, 51, 126.
(67) Yu, F.; Phalak, N.; Sun, Z.; Fan, L. Ind. Eng. Chem. Res. 2012, 51, 2133.

(68) Zhang, K.; Li, X. S.; Chen, H.; Singh, P.; King, D. L. J. Phys. Chem. C 2016, 120 (2), 1089.

(69) Zhang, K.; Li, X. S.; Li, W. Z.; Rohatgi, A.; Duan, Y.; Singh, P.; Li, L.; King, D. L. Adv. Mater. Interfaces 2014, 1 (1400030), 1400030-1400031.

(70) Lee, C. H.; Lee, K. B. Appl. Energy 2017, 205 (April), 316-322.

(71) Papaioannou, E. I.; Qi, H.; Metcalfe, I. S. J. Memb. Sci. 2015, 485,87 .

(72) Hammer, B.; Hansen, L. B.; Kehlet, J. Phys. Rev. B Condens. Matter 1999, 59, 7413.

(73) Perdew, J. P.; Burke, K.; Ernzerhof, M. Phys. Rev. Lett. 1996, 77 (3), 3865 .

(74) Kresse, G.; Furthmuller, J. Phys. Rev. B 1996, 54 (16), 11169.

(75) Kresse, G.; Furthmuller, J. Comput. Mater. Sci. 1996, 6, 15. 


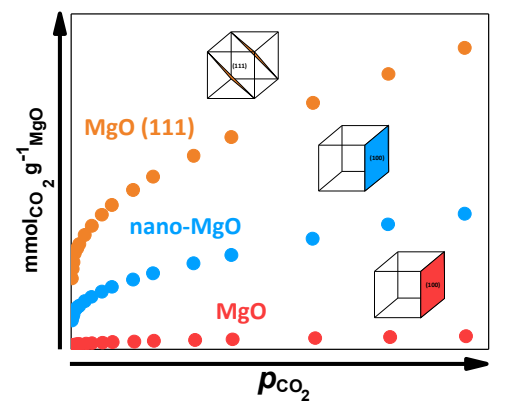

